\title{
Acidosis, CTCAE
}

National Cancer Institute

\section{Source}

National Cancer Institute. Acidosis, CT CAE. NCI Thesaurus. Code C143259.

A disorder characterized by abnormally high acidity (high hydrogen-ion concentration) of the blood and other body tissues. 